\title{
Research on Design and Construction Quality and Technical Supervision Network Information Platform in Airport Economic Zone
}

\author{
Yang Changhui \\ School of Business, Zhengzhou University, Zhengzhou, Henan, China, 450001 \\ yangchanghui@zzu.edu.cn
}

\begin{abstract}
Information technology has been widely used in airport economic zone in the daily management of the enterprise and government. The use of it to build quality and technical supervision information platform can realize the quality and technical supervision of law enforcement electronic and informatization, achieve supervise management informatization, decision support intelligent, business process standardization and information exchange release automation. At first, this paper analyzes the business requirements and functional requirements of quality and technical supervision information platform, and then discuss the overall structure and network topology structure of the information platform, analyses the design and construction of the information platform, and finally discusses the main application system of the information platform. Platform application helps to enhance the institutionalization and standardization of quality and technical supervision, standardize the market economic order, improve product quality, engineering quality and service quality and enhance the international competitiveness of economic zone industry, enterprises and products.
\end{abstract}

Keywords: Quality Technical Supervision, Information Platform, System Structure, Network Structure, Airport Economic Zone

\section{Introduction}

At present, under the trend of economic globalization and regional economic integration, the world science and technology changes with each passing day, the competition in overall national strength is becoming increasingly fierce. With modern information technology to improve quality and technical supervision system, it can realize the quality and technical supervision of law enforcement electronic and informatization, promote the quality and technical supervision department to turn into management service, improve the efficiency and law enforcement transparency of quality and technical supervision work, strengthen the institutionalization and standardization of quality and technical supervision work, standardize the market economic order and ensure the healthy development of the socialist market economy. The construction of airport economic zone quality and technical supervision information platform helps to give full play to the functions of service economy, promote development, strict control and secure the state and comfort the people of the quality and technical supervision work, helps to fully implement the "quality win" strategy, improve product quality, engineering quality and service quality and enhance the international competitiveness of economic zone industry, enterprises and products[1-3]. 


\section{Overview of Airport Economic Zone Quality and Technical Supervision Information Platform}

Airport economic zone quality and technical supervision information platform is a quality and technical supervision information network platform that is relying on e-government platform, construction standard unified, perfect functions, safe and reliable. the comprehensive construction quality and technical supervision business computer management system, establish quality and technical supervision business scale data-base, increase the degree of information resources sharing, the construction of the informatization standard system of quality and technical supervision[4]. Overall build quality and technical supervision business computer management system, establish quality and technical supervision services database group, improve the degree of sharing of information resources, build quality and technical supervision informatization standard system.

By using the informationization construction of airport economic zone quality construction supervision information platform, improve the level of law enforcement of quality supervision, improve the ability of market regulation and the ability of rapid response of the quality and safety monitoring, improve the administrative management mode, improve the efficiency of quality inspection work, promote the development of foreign economic relations and trade, protect the development of national industry, promote open government, provide a wide range of information consulting services for the public.

Through airport economic zone quality and technical supervision information platform, can simplify the administrative examination and approval procedures, improve the speed of administrative examination and approval, improve the work mode of administrative examination and approval such as declaration, process management, data transmission, information release and so on, improve work efficiency, reduce administrative examination and approval links, save management costs, improve capital utilization, bring more convenient for enterprises[5]. In terms of quality and technical supervision, certification and accreditation, metrology, standardization and special equipment safety supervision of full implementation of information management, strengthen internal management, standardize business way, finally realizes the network of administrative examination and approval, supervision and management of information, intelligent decision support, business process standardization, information exchange release automation, comprehensive promotion the level of law enforcement of quality supervision, strengthen market supervision and the ability of rapid response of the quality and safety monitoring, improve quality administration[6].

\section{Business and Functional Requirements Analysis of Airport Economic Zone Quality and Technical Supervision Information Platform}

\subsection{Business Requirements Analysis}

3.1.1. Quality Supervision Business: Using computer manage quality and technical supervision business, can achieve the regulatory functions of objects and work process in the business such as quality management, quality supervision, measurement, certification and accreditation, standardization, and special equipment safety supervision as well as food production and processing link security supervision. Monitoring of the process of quality supervision business, real-time understanding of quality supervision business information and timely 
grasping the information is convenient to collect all kinds of information and comprehensive statistical analysis. At the same time to provide resources to support for information release, provide service for the public. It mainly includes:

1. Law enforcement anti-counterfeiting, anti-counterfeiting fidelity rapid response

Online report, impact report reward, complaints business center management, case-source information collection, law enforcement supervision rapid response processing and information transmission, enterprise "blacklist" (database) fake identification information, the supervision and management of product anticounterfeiting and so on.

2. Product quality and technical supervision management

Product quality and technical supervision spot check, food quality and safety market access, quality inspection institution management, national survey of quality and so on.

\section{Standardization}

Mainly includes: Local standard management, adopt international standard management, standardization production standard management, enterprise standardization standard evaluation, enterprise standard filing management, enterprise standard registration management, agricultural standardization management, inspection of the implementation of mandatory standards, standard publicizing work.

\section{Equipment supervision}

Mainly includes: Dynamic management of supervisory work, dynamic management on the equipment, dynamic management of production units, dynamic management of testing agency, dynamic management of personnel, dynamic management of the inspection work, accident dynamic management and administrative approval, supervision and inspection and so on. Realization of administrative examination and approval, supervision and inspection, and other businesses handling and dynamic management of all aspects of monitoring, equipment, production units, agencies, personnel, accident, inspection, etc..

\section{Laws and regulations}

Mainly includes the national aspects of quality supervision laws, administrative regulations, local regulations, and department rules and regulations, making it easy for users to query related laws and regulations.

3.1.2. Quality Supervision Declaration and Approval of Business: Through the construction of the system for computer declare for examination and approval of quality supervision, achieve all kinds of business registration of enterprises, licenses and other applications accepted. Through the online application to inspection, examination and approval or certification of enterprises, feedback the result to the applicant enterprise, provide more convenient service for the enterprise, exempt from tedious journey time and paper in the office, Simplify notification and approval process, improve work efficiency and reduce management costs[7-8]. It can be divided into:

\section{The examination and approval management}

Take the examination and approval business as the main line, to realize the management of application acceptance, examination and approval, issuance, regular inspection, review and follow-up monitoring process, at the same time, the process and result of the application and approval will be timely summary to the AQSIS. 
Simplify notification and approval process, provide more convenient service for the enterprise and improve work efficiency.

\section{Registration management}

Registration management is the management that takes business registration, record management as the main line, to achieve registration, record application, examination and approval, the follow-up management such as process, at the same time, achieving registration, check the record business information, statistics and summary reporting capabilities.

\section{Information service}

By information service management capabilities, achieve information release, to provide information consultation service for society, enterprises and the public. It mainly includes: comprehensive information service, quality information service, WTO/TBT, SPS notification business management, WTO/TBT mandatory standard notification management, products anti-counterfeiting fidelity information services and so on.

\section{Data storage and query}

Storage and query requirements to create a series of database for quality business decision and providing effective information for government and the public, satisfying the need of information query. It includes enterprise basic information, the quality of the product information, anti-counterfeiting information, institutions of quality information and human resources information and so on.

\section{Daily management}

(1) Integrated office management

Integrated office management mainly has six aspects: office management, personal affairs, performance management, organ culture, system management, system interface, as shown in Figure 1. Function is described below.

Office management main features include: catalog management, reminders supervision, notification notices, meeting management, approval documents, dispatch management, receipt management.

Personal affairs main features include: today work, personal documents, scheduling, e-mail, SMS alerts, contacts, personal settings.

Organ culture main features include: electronic journals, information dissemination, online schools, regulations, technical exchanges, electronic forums, employee suggestions.

Performance management mainly includes the performance targets, measure indicators, performance considerations, performance evaluation and continuous improvement five aspects.

System management mainly includes: security and backup, system maintenance, rights management, process settings, departments and personnel.

System interface: provides standards, specifications, safety interface to related system for easy transfer of data.

(2)Logistics services

Mainly includes material management and vehicle management, etc..

(3) Information release

Mainly completes relevant information collection, processing and release of quality control, making it easy for users to timely and accurately understand the related information of quality control. 


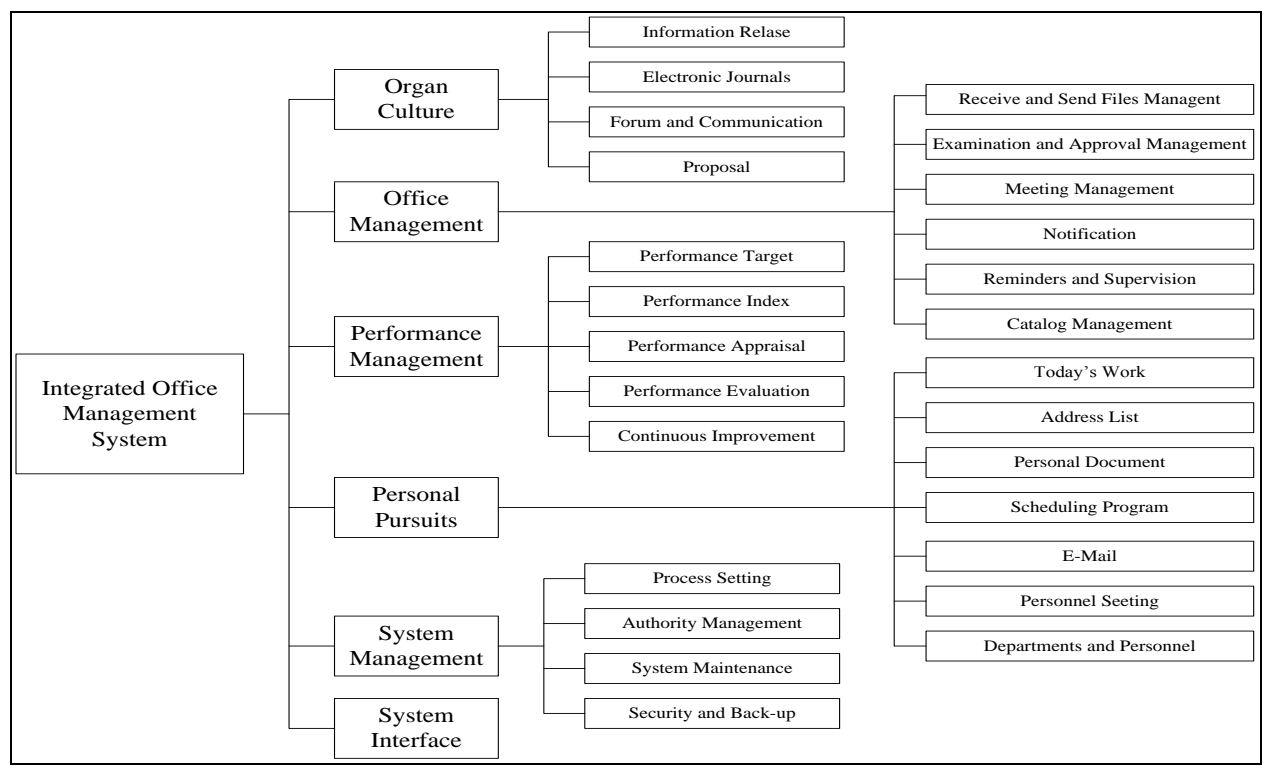

Figure 1. Integrated Office System Structure

\subsection{Functional Requirements Analysis}

3.2.1. Quality and Technical Supervision Comprehensive Business System and Quality Control Business Dynamic Supervision System: Law enforcement anticounterfeiting rapid response, quality of enterprise credit information management, WTO/TBT-SPS notification, appraisal, advisory and risk early warning, measuring business supervision management, national mandatory product certification regulation, national standard reporting and information service, product quality and technical supervision management system in accordance with the unified administration of the national requirements for system deployment.

3.2.2. Integrated Office Management System: Mainly includes office management, organ culture, personal affairs, system management, education training, personnel management, financial management, as well as the system interface.

\subsection{3. "Three Separation" System for Examination and Approval of Administrative} business: The system is one of the main application system of airport economic zone quality and technical supervision information platform, to avoid excessive concentration of power prone to corruption from the systems and procedures and reduce the cost of enterprises and the masses. It changes the "one hand" work style that original administrative license and market access work follows - selfacceptance, review, approval and supervision by the competent business department, the first to introduce administrative licensing business review, approve, supervise three separation in the national quality supervision system.

3.2.4. Video Conference and Voice Communication System: Web-based multimedia network video conference system only needs a computer connected to the Internet and telephone that can make the quality supervision system personnel staying at home achieve text, sound and images in real-time communication, can make them communicate in real-time from anywhere with anyone face to face meetings to achieve. 
3.2.5. "12365" Quality Supervision Customer Service Center: Main functions include: report complaints, business consulting, SMS and voice services.

3.2.6. Quality Supervision Personnel Training System: Implementation of quality supervision personnel business level, knowledge, skills and other aspects of training, quality supervision personnel according to their own quality condition can choose different training content, providing business level.

3.2.7. Information Service System of Quality Supervision: Mainly includes: achieve product quality information, anti-counterfeiting information, product sampling results information, corporate qualification information, and the release of information such as relevant circulars, laws and regulations.

\section{System Overall Structure and Network Structure}

\subsection{System Overall Structure}

The overall structure of airport economic zone quality and technical supervision information platform is supported by network infrastructure layer, data support layer, application support layer, application layer and access layer [9, 10]. System overall structure is shown in Figure 2.

Network infrastructure layer (computer network and hardware platforms), is composed by the quality supervision system WAN, LAN and running computer equipment.

Data supporting layer (Industry Data Center + information channels). Industry data center based on various types of quality and technical supervision data as the main content, relying on database management and data warehouse technology, in accordance with uniform standards, establish the system of quality supervision business database group for organization, management, maintain and update. Information channel is the technology system that through the "Gold Project" business data network achieve the information exchange and sharing among AQSIQ data center, the provinces, districts data centers and the relevant units information systems.

Application support layer (e-government application supporting platform) provides government affairs management information system and the operation supporting environment of the socialized service system, and is used to build egovernment application system directly, including application support services, business building, business integration and basic services.

Application layer (e-government application information system) is a variety of e-government applications structured on the application support layer. Under the network environment, it realizes informatization of business supervision and administration, business examination and approval management and information service. It is the level of "Gold Project" for the end user.

Access layer (comprehensive portal website) is the entrance of the e-government system. Through the access to government affairs management information system, it provides internal business informatization application and social management and information services to social users.

Information security system at all levels provides "Gold Project" confidentiality, integrity, availability and other security services.

Standard and normal. Through the "Gold Project" construction, form a unified government affairs management information system construction standard specification. implement government affairs management information, meet the social public demand such as government affairs public, online declaration and 
information inquiry, so as to promote the development of the system construction of e-government.

\begin{tabular}{|c|c|c|c|c|c|c|}
\hline Access Layer & \multicolumn{4}{|c|}{ Comprehensive Portal Website (CA Certification) } & $\begin{array}{c}\text { User } \\
\text { Behavior }\end{array}$ & \multirow{5}{*}{$\begin{array}{l}\text { Standards } \\
\text { atd Normas }\end{array}$} \\
\hline $\begin{array}{l}\text { Application } \\
\text { Layer }\end{array}$ & $\begin{array}{l}\text { Quality Inspection Service } \\
\text { Supervision and Management } \\
\text { System }\end{array}$ & \multicolumn{2}{|c|}{$\begin{array}{l}\text { Quality Inspection } \\
\text { Information Service } \\
\text { Management System }\end{array}$} & $\begin{array}{l}\text { Quality Inspection Business } \\
\text { Examination and Approval } \\
\text { Management System }\end{array}$ & $\begin{array}{l}\text { Application } \\
\text { Authority } \\
\text { Safety }\end{array}$ & \\
\hline $\begin{array}{l}\text { Application } \\
\text { Support Layer }\end{array}$ & \multicolumn{4}{|c|}{$\begin{array}{l}\text { Application Support Platform } \\
\text { Support Service: Engine of Rule, Workflow and Business Processing } \\
\text { Business Component: Component of Application, User Interface and Data Support Exchange } \\
\text { System Integration: Integration of Data and Application, Platform of Visit and Right Management } \\
\text { Basic Service: Domain Name Range, Catalog Service, Service of Catalog, Security and Management }\end{array}$} & \multirow[t]{2}{*}{$\begin{array}{l}\text { Safety } \\
\text { Scurity } \\
\text { System }\end{array}$} & \\
\hline $\begin{array}{l}\text { Data Support } \\
\text { Layer }\end{array}$ & $\begin{array}{l}\text { Industry Data Center } \\
\text { Basic Data: Basic Code, Database } \\
\text { Derivative Data: Data Warehouse }\end{array}$ & luster & $\begin{array}{l}\text { Informa } \\
\text { Data Exchan } \\
\text { Data Transm } \\
\text { Data Termin }\end{array}$ & $\begin{array}{l}\text { on Chanel } \\
\text { e Platform } \\
\text { sion Chanel } \\
\text { : Collection and Exchange Terminal }\end{array}$ & & \\
\hline $\begin{array}{c}\text { Network } \\
\text { Infrastructure }\end{array}$ & $\begin{array}{r}\mathrm{Ru} \\
\text { Network, }\end{array}$ & $\begin{array}{l}\text { ing } \\
\text { erver }\end{array}$ & $\begin{array}{l}\text { t Environn } \\
\text { Dperation } \mathrm{S}\end{array}$ & stem etc. & $\begin{array}{l}\text { Network } \\
\text { Safety }\end{array}$ & \\
\hline
\end{tabular}

Figure 2. System Structure of Airport Economic Zone Quality and Technical Supervision Information Platform

\subsection{Platform Network System}

4.2.1. Platform Network System Design Target and Principle: Platform network system design mainly follows real-time, maturity, advancement, reliability, security, scalability, flexibility and other targets.

4.2.2. Network System Design Principles: Platform network system design mainly follows the following principles: the user's actual and potential demand, technology advancement, protecting the user's investment, the degree of technology standardization, interconnection of different equipment manufacturer, the scalable and manageability of the network.

4.2.3. Network System Design Requirements: 1 . Business backbone network design requirements.Business backbone network construction is built based on the full analysis of the current situation and business basis of quality supervision system; it should be able to meet the needs of multi-service and high-bandwidth applications of quality supervision system.

2. Network security requirements

Network security is the basis for the safe operation of information systems and the key to ensure the safe operation of the systems. Network system security requirements include the network border security requirements, invasive monitoring and real-time monitoring requirements, security incident response and handling requirements analysis.

Physical security is the precondition of the safe operation of the information system and it is an important part of the security system. Physical security is related to environmental safety, equipment safety and media safety three parts, which are for the environment in computer information systems, the equipment used, the media contained for safety protection. 
4.2.4. The Overall Structure of the Network Platform: Quality supervision network platform should have high-speed data exchange, IDC center, IP telephone video conference, video on demand, e-mail services, file transfer services and other functions, and also take into account the needs of the access of mobile office information point and product quality electronic supervision network interface. Network construction requires the network can operated in a high speed, reliably and safely [11]. The overall structure of the network platform design as shown in Figure 3.

\subsection{The Overall Structure of the Application System}

The application system overall structure of airport economic zone of quality and technical supervision information platform is as shown in figure 4. Mainly been divided into foundation platform and application system.

4.3.1. The First Layer: Basic Platform: Adopt advanced integrated technology, construct the information processing platform of quality supervision information; distinctly improve interconnection, interflow and interoperability of the system and information sharing. Foundation platform is mainly used to develop application system at all levels in the application system. It provides including system management, process control, data maintenance, detain query, report forms printing, statistical summary and other public function modules. Foundation platform includes application support, data support two levels.

4.3.2. The Second Layer: Application System: Construct the eight major subsystems based on unified foundation platform. Mainly include: Quality and technical supervision comprehensive business system, quality control business dynamic supervision system, integrated office management system, video conference and voice communication system of quality and technical supervision, "Three separation" system for examination and approval of administrative business, "12365" quality supervision customer service center, quality control personnel training system, information service system of quality control [12].

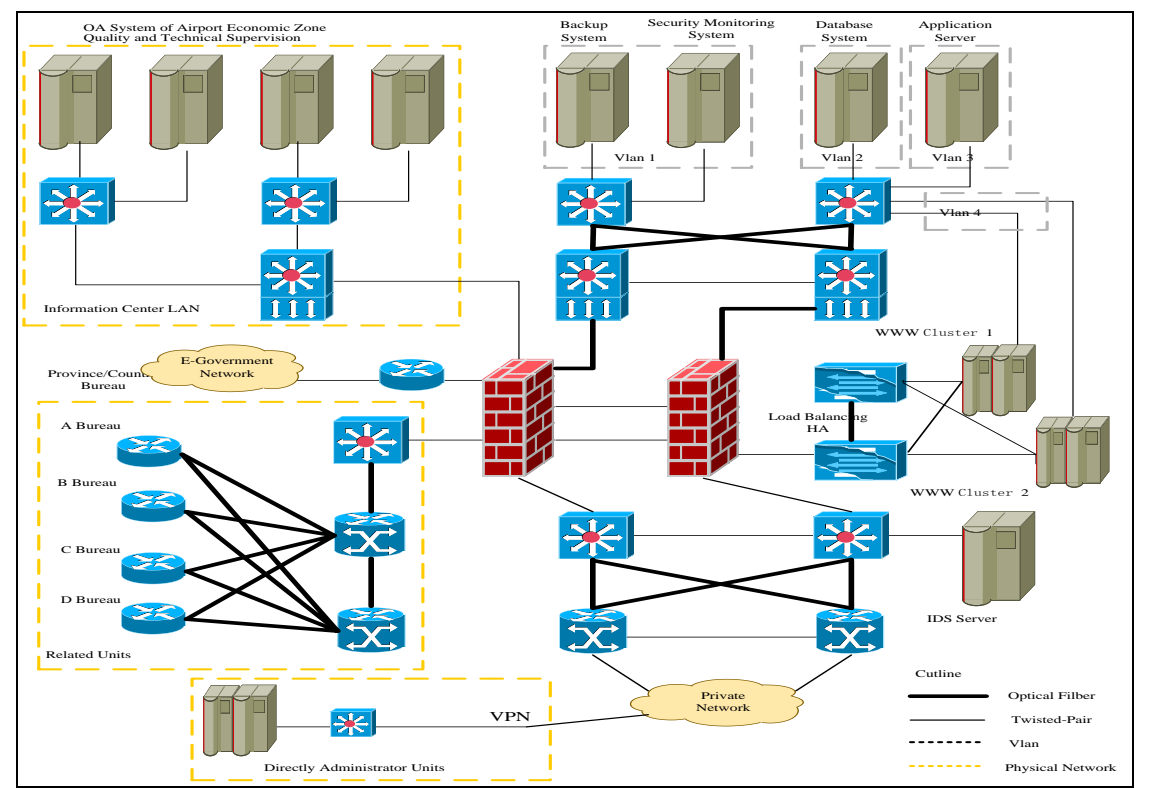

Figure 3. Quality and Technical Supervision Information Platform Network Structure 


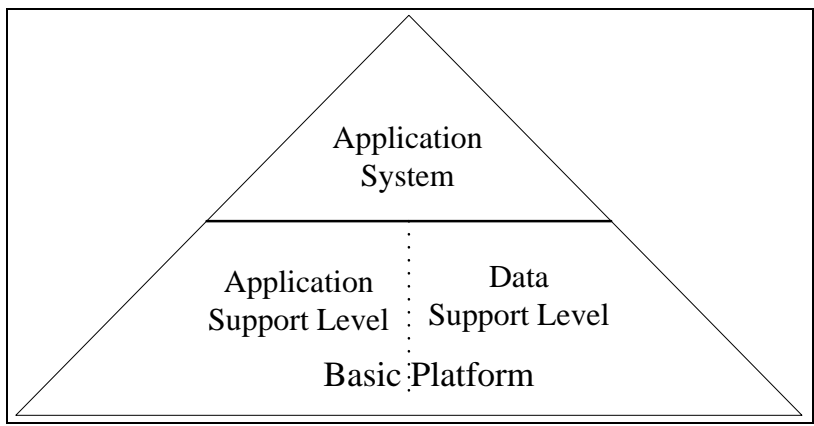

Figure 4. Application System Overall Structure of Airport Economic Zone of Quality and Technical Supervision Information Platform

\section{Conclusion}

By means of informationization to construct airport economic zone quality construction supervision information platform helps to improve the level of quality supervision law enforcement, improve market regulatory capacity and rapid response ability of quality safety monitoring, improve the administrative management mode, improve the efficiency of quality inspection work and provide a wide range of information consulting services for public. This paper analyzes the business requirements and functional requirements of quality and technical supervision information platform, discusses the general structure and network topology structure of the information platform, analyses the design and construction of information platform, and discusses the main application system of information platform.

\section{Acknowledgments}

This paper was supported by NSFC (71272207, 71301150, U1304705, U1404704), NSSF 13BGL061, 10YJC630326 and 14YJC630126 (Humanity and Social Science Foundation of Ministry of Education).

\section{References}

[1] J. Bo, C. Ming and G. Guanqing, "Distributional and central unifies call center, Computer application", no. 7, (2002), pp. 46-51.

[2] J. Geurt and G. Koole, "Managing uncertainty in call centers using Poisson mixtures", Applied Stochastic Models in Business and Industry, vol. 17, (2001), pp. 307-318.

[3] J. Luping, L. Kelu and T. Hua, "Based on three structures disperser -like call center system", Computer application, no. 12, (2004), pp. 66-73.

[4] N. Prindezis, C. T. Kiranoudis, "An internet-based logistics management system for enterprise chains", Journal of Food Engineering, vol. 70, no. 3, (2005), pp. 373-381.

[5] J. Santa, "Telematic platform for integral management of agricultural/perishable goods in terrestrial logistics", Computers and Electronics in Agriculture", vol. 80, (2012), pp. 31-40.

[6] J. D. Nelson and C. Mulley, "The impact of application of new technology on public transport service provision and the passenger experience: A focus on implement in Australia", Research In Transportation Economics, vol. 39, no. 1, (2013), pp. 300-308.

[7] J. Fu, Z. J. Zhang, X. L. Jin and Z. Q. Hao, "Smart Subway Information Platform based on Internet of Things, International Journal of Hybrid Information Technology", vol. 6, (2013), pp. 177-186.

[8] T. Levendovszky, A. Dubey, W. R. Otte, D. Balasubramanian, A. Coglio, S. Nyako, W. Emfinger, P. Kumar, A. Gokhale and G. Karsai, "Distributed Real-Time Managed Systems: A Model-Driven Distributed Secure Information Architecture Platform for Managed Embedded Systems", IEEE Software, vol. 31, no. 2, (2014), pp. 62-69.

[9] C. Li, X. Zhang and L. Li, "Research on Comparative Analysis of Regional Logistics Information Platform Operation Mode Based on Cloud Computing", International Journal of Future Generation Communication \& Networking, vol. 7, no. 2, (2014), pp. 73-80. 
[10] Y. Changhui and W. Xi, "Research on Construction Exhibition Integrated Information Service System in Airport Economic Zone", Computer Modelling and New Technologies", vol. 18, no. 12, (2014), pp. 232-238.

[11] Y. Changhui, "Research on Evolution of Information System and It's Implemented Economic Evaluation", International Journal of Hybrid Information Technology”, vol. 8, no. 1, (2015), pp. 217226.

[12] Y. Changhui, "Research on Building Electronic Port Information Platform of Airport Economic Zone", Open Cybernetics and Systemics Journal, no. 9, (2015), pp. 268-274.

\section{Author}

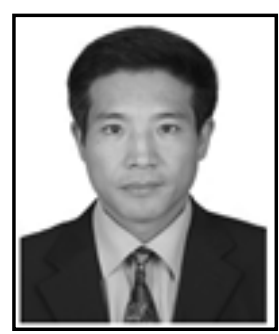

Yang Changhui, Graduated from Central South University, and now working at Business School of Zhengzhou University, the main research directions include operation management, supply chain management and management information system. 